\title{
Modelling the ability of source control measures to reduce inundation risk in a community-scale urban drainage system
}

\author{
Chao Mei ${ }^{1}$, Jiahong Liu ${ }^{1,2}$, Hao Wang ${ }^{1,2}$, Weiwei Shao ${ }^{1}$, Lin Xia ${ }^{1}$, Chenyao Xiang ${ }^{1}$, and Jinjun Zhou ${ }^{1}$ \\ ${ }^{1}$ China Institute of Water Resources and Hydropower Research, State Key Laboratory of Simulation and \\ Regulation of Water Cycle in River Basin, China, Beijing 100038, China \\ ${ }^{2}$ Engineering and Technology Research Center for Water resources and Hydroecology of the \\ Ministry of Water Resources, Beijing 100044, China \\ Correspondence: Jiahong Liu (liujh@iwhr.com)
}

Received: 19 December 2017 - Revised: 2 February 2018 - Accepted: 5 February 2018 - Published: 5 June 2018

\begin{abstract}
Urban inundation is a serious challenge that increasingly confronts the residents of many cities, as well as policymakers, in the context of rapid urbanization and climate change worldwide. In recent years, source control measures (SCMs) such as green roofs, permeable pavements, rain gardens, and vegetative swales have been implemented to address flood inundation in urban settings, and proven to be cost-effective and sustainable. In order to investigate the ability of SCMs on reducing inundation in a community-scale urban drainage system, a dynamic rainfall-runoff model of a community-scale urban drainage system was developed based on SWMM. SCMs implementing scenarios were modelled under six design rainstorm events with return period ranging from 2 to 100 years, and inundation risks of the drainage system were evaluated before and after the proposed implementation of SCMs, with a risk-evaluation method based on SWMM and analytic hierarchy process (AHP). Results show that, SCMs implementation resulting in significantly reduction of hydrological indexes that related to inundation risks, range of reduction rates of average flow, peak flow, and total flooded volume of the drainage system were 28.1-72.1, 19.0-69.2, and 33.9-56.0\%, respectively, under six rainfall events with return periods ranging from 2 to 100 years. Corresponding, the inundation risks of the drainage system were significantly reduced after SCMs implementation, the risk values falling below 0.2 when the rainfall return period was less than 10 years. Simulation results confirm the effectiveness of SCMs on mitigating inundation, and quantified the potential of SCMs on reducing inundation risks in the urban drainage system, which provided scientific references for implementing SCMs for inundation control of the study area.
\end{abstract}

\section{Introduction}

The risk of urban inundation has been growing rapidly in recent years due to global urbanization and climate change (Zhao et al., 2016). Over the past several decades, increasing surface imperviousness caused by rapid urbanization has led to significant changes in the characteristics of the urban hydrologic cycle (Palla and Gnecco, 2015). In general, the reduction of native vegetation and the thinning of natural soils related to urbanization reduces the infiltration and storage of water (Jacobson, 2011), leading to increasing runoff rates and volumes and ultimately increasing the hy- draulic load for urban drainage systems (Kim et al., 2015). However, increased surface runoff, faster runoff concentration, and higher peak flow rates can exceed an urban system's drainage capacity and cause inundation, resulting in traffic interruption, economic loss, pollution, and health issues (Dash et al., 2016). Improving the drainage capacity in rapidly urbanizing areas is a straightforward method for reducing inundation risk, and a significant improvement can be achieved in most cases (Pochwa et al., 2017). However, simple and isolated improvements to drainage capacity are now proven to be unsustainable, costly, and even impractical because of great uncertainties in the broader context of land- 


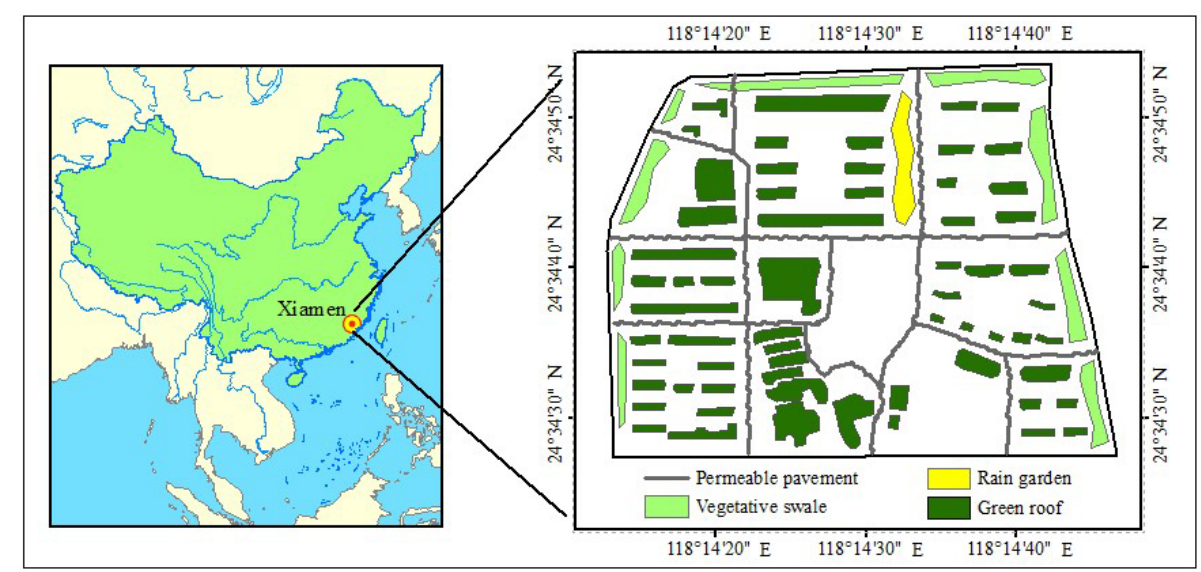

Figure 1. Location of the study area and the sketch map of SCMs settings in YN.

scape and climate change, particularly in densely urbanized areas. SCMs are facilities capable of effectively storing and infiltrating storm water runoff, usually involving green infrastructure such as green roofs, permeable pavements, vegetative swales, rain gardens, and bio-retention systems (Todeschini et al., 2012). The implementation of SCMs is usually low-cost and environmentally friendly and the benefits for runoff reduction have been confirmed by many studies at different scales. Hu et al. (2017) reported that permeable pavements are effective at mitigating flood inundation hazards in urban watersheds. Liu et al. (2014) assessed the effectiveness of green infrastructure on urban flooding reduction at a community scale and showed that total runoff reduction ranged from $85-100 \%$ and peak flow was reduced $92.8-100 \%$. Pyke et al. (2011) illustrated the potential benefits of a common LID practice for increasing the resilience of communities to changing precipitation patterns. This objective of this study was to determine whether SCMs can reduce the inundation risks in urban drainage systems and assess the reduction under different rainfall conditions using scenario analysis.

\section{Materials and methods}

\subsection{Site description and data preparation}

The study area, Yangtang Neighbourhood (YN), is a residential community covering 62.87 ha (Fig. 1, 24 $34^{\prime} 18^{\prime \prime}-$ $24^{\circ} 35^{\prime} \mathrm{N}, 118^{\circ} 14^{\prime} 02^{\prime \prime}-118^{\circ} 14^{\prime} 59^{\prime \prime} \mathrm{E}$ ) in Xiamen, an important harbour city on the southeast coast of China. The average annual precipitation in YN is $1388 \mathrm{~mm}(1985-2014)$, and over the course of a year the distribution of precipitation is extremely uneven, with rainfall occurring mainly in the flood season, from May-September, there is an increasing trend in precipitation of $\mathrm{YN}$ according to local investigation. The main land uses have changed from village, bare soil, farmland, and ponds to roads, housing, and other build- ings, leading to an increase in the proportion of impervious surfaces from 18 to $68 \%$. Rapid urbanization has therefore dramatically changed the urban water cycle, leading to urban flooding and the inundation of drainage systems.

\subsection{Modelling the urban drainage system in $\mathrm{YN}$}

The Storm Water Management Model (SWMM), developed by the United States Environmental Protection Agency, is an integrated simulation platform for urban water systems; version 5.1 was used in this study. SWMM can be used for dynamic hydrology-hydraulic and water quality simulation and has been widely used in urban water system simulations throughout the world (Chui et al., 2016; Zhu et al., 2016). The SWMM model solved the Saint-Venant equations and modelling drainage system with dynamic wave, is suitable for urban drainage system in a community-scale in this study. The SWMM platform was used to develop an integrated simulation model of the urban drainage system in $\mathrm{YN}$, using both logical parameters based on earlier experience and local knowledge while consulting the SWMM user manual and previous research. The modelled area was divided into 12 sub-catchments, 25 Junctions, and 37 conduits (Fig. 2) and used a simulation time step of 1 min with a total simulation time of $6 \mathrm{~h}$.

\subsection{Inundation risk evaluation methods}

\subsubsection{Indices for the evaluation of inundation risk}

Urban drainage systems are mainly defined by catchment area, underlying surfaces, and pipe networks. A riskevaluation index for these systems should include indices such as land use, flood amount, and drainage networks that should be built. Nine indices are selected: inundation duration, largest water flow, total flood amount, runoff coefficient, impermeable surface area, catchment area, and the diameter, gradient, and congested proportion of pipes down- 
Table 1. Normalized weights of the risk evaluation indices.

\begin{tabular}{llr}
\hline Categories & Indices & Normalized weight \\
\hline Hydraulic & Inundation duration & 0.1955 \\
& Largest water flow & 0.1135 \\
& Total flood amount & 0.3076 \\
Environmental & Runoff coefficient & 0.0553 \\
& Impervious area proportion & 0.0481 \\
& Catchment area & 0.0993 \\
Drainage & Diameter of downstream pipe & 0.0944 \\
& Gradient of downstream pipe & 0.0479 \\
& Congested proportion of downstream pipe & 0.0444 \\
\hline
\end{tabular}

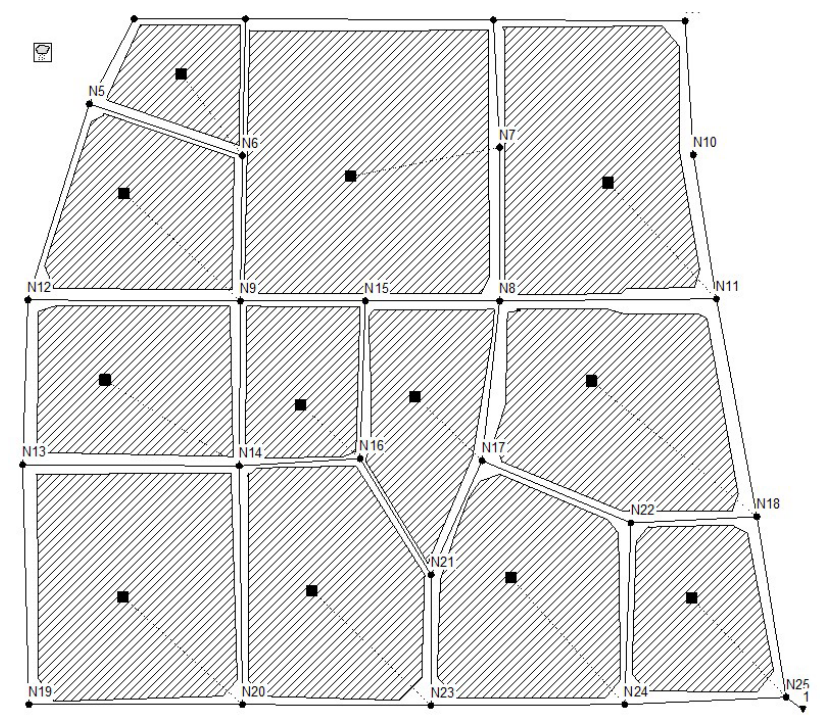

Figure 2. Drainage system modeled on YN.

stream of each manhole (Wang, 2010). We then classified these into three independent groups: hydraulic, environmental, and drainage.

\subsubsection{Calculation of inundation risks}

In this study, the inundation risk of each manhole in the YN drainage system was defined as a weighted sum as follows:

$R=\sum_{i=1}^{m} X_{i} W_{i}$

Where $R$ is the inundation risk value of each manhole, $m$ is the number of evaluation indices, $i$ is the serial number of the indices, $X_{i}$ is the normalized value of each index, and $W_{i}$ is the normalized weight of the index $X_{i}$. In this study, the greater the value of $R$, the higher the inundation risk of the manhole. Thus, the calculated $R$ value of each manhole under different rainfall scenarios could be used to evaluate inundation risk (Islam et al., 2013).
To properly evaluate the inundation risk, appropriate weights for the indices needed to be determined. We used analytic hierarchy process (AHP) in this study due to its unique advantages when the elements of certain decisions are difficult to quantify or compare (Jiao et al., 2017). The detailed principles and procedures of AHP can be found in the literature (Jenifer and Jha, 2017). We consulted 10 high-level experts in the fields of urban planning, city management, environment risk, water supply, and drainage when considering the proper weights for indices used in the AHP method, settling on the weights for inundation risk evaluation indices presented in Table 1.

\subsection{Simulation scenarios}

\subsubsection{SCM scenarios}

Although a variety of SCMs can achieve runoff reduction, not all can be adapted to a specific area; therefore, the selection of site-appropriate SCMs is important. After considering these factors with relation to $\mathrm{YN}$, green roofs, rain gardens, permeable pavements, and vegetative swales were selected as those that could be implemented most effectively. In this plan, all SCMs are work together to reduce surface runoff and storm water load in the urban drainage system. The design and planning work for the YN SCMs was conducted by the Xiamen Municipal Engineering Design Institute Co., Ltd. Most roofs will be converted into green roofs, with a total area of $125000 \mathrm{~m}^{2}$; rain gardens with a total area of $30000 \mathrm{~m}^{2}$ will collect runoff; most roads will be converted to pervious surfaces such as permeable asphalt, concrete, and brick with a total area of $129000 \mathrm{~m}^{2}$; and green space surrounding $\mathrm{YN}$ will be converted to vegetative swales with a total area of $42000 \mathrm{~m}^{2}$ (Fig. 1).

\subsubsection{Storm scenarios}

The SWMM model developed for this study can be used to simulate annual rainfall or a singular event. As the main objective of this study was to assess the effects of SCM implementation on the $\mathrm{YN}$ urban drainage systems, we chose to model short-term rainfall using $2 \mathrm{~h}$ design storm rainfalls 


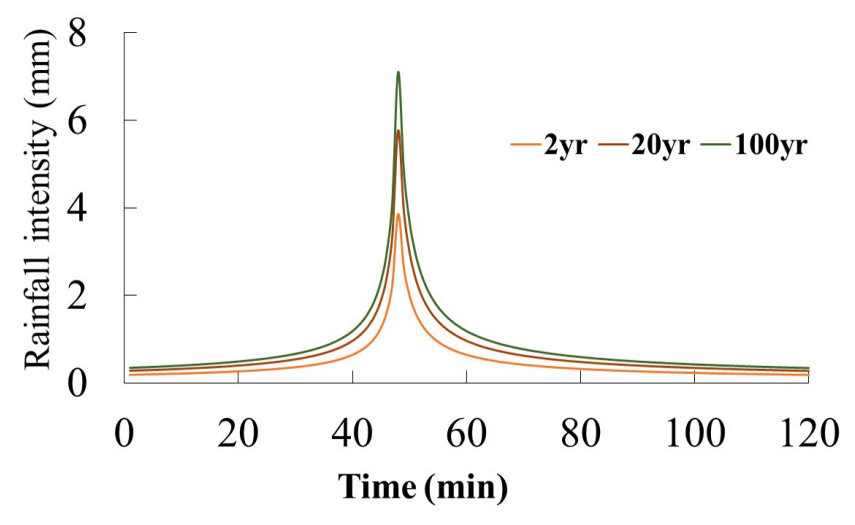

Figure 3. Synthetic rainfall events with different return periods modelled for YN.

with a 1 min time step and different return periods as calculated by the storm intensity formula for Xiamen, which is a local standard established by the department of municipal administration:

$q=\frac{1432.348(1+0.582 \lg P)}{(t+4.56)^{0.633}}$

Where $i$ is the storm intensity in $\mathrm{L} \mathrm{min}^{-1} \mathrm{ha}^{-1}$ ), $P$ is the storm return period in years, and $t$ is the convergence time in $\min$.

In order to evaluate the reduction effects under different rainfall intensities, we generated six $2 \mathrm{~h}$ synthetic storms with return periods of $2,5,10,20,50$, and 100 years (partially showed in Fig. 3) and used these six events to model the effects on YN's urban drainage system. Due to a lack of research on rainfall patterns in Xiamen, the widely used Chicago-storms synthetic rainfall pattern was selected to simulate these rainfall events with different return periods, with the peak occurrence of all events set to be 0.4. Finally, the drainage system of YN are modelled under two scenarios: before implementation of the SCMs (baseline, BL) and after implementation (SCM).

\section{Results and discussion}

\subsection{Overall hydrologic performance}

The implementation of SCMs changes the hydrological cycle of an area by increasing the storage of rainwater, thus delaying peak flow, reducing flood volume, and mitigating flood effects. In this study, we used hydrographs and hydrologic performance indices to evaluate the impacts of SCM implementation; Fig. 4 shows the outfall runoff hydrographs for YN under the BL and SCM scenarios.

As shown in Fig. 4, SCMs implementation resulting in significantly reduction of hydrological indexes that related to inundation risks, range of reduction rates of average flow, peak flow, and total flooded volume of the drainage system
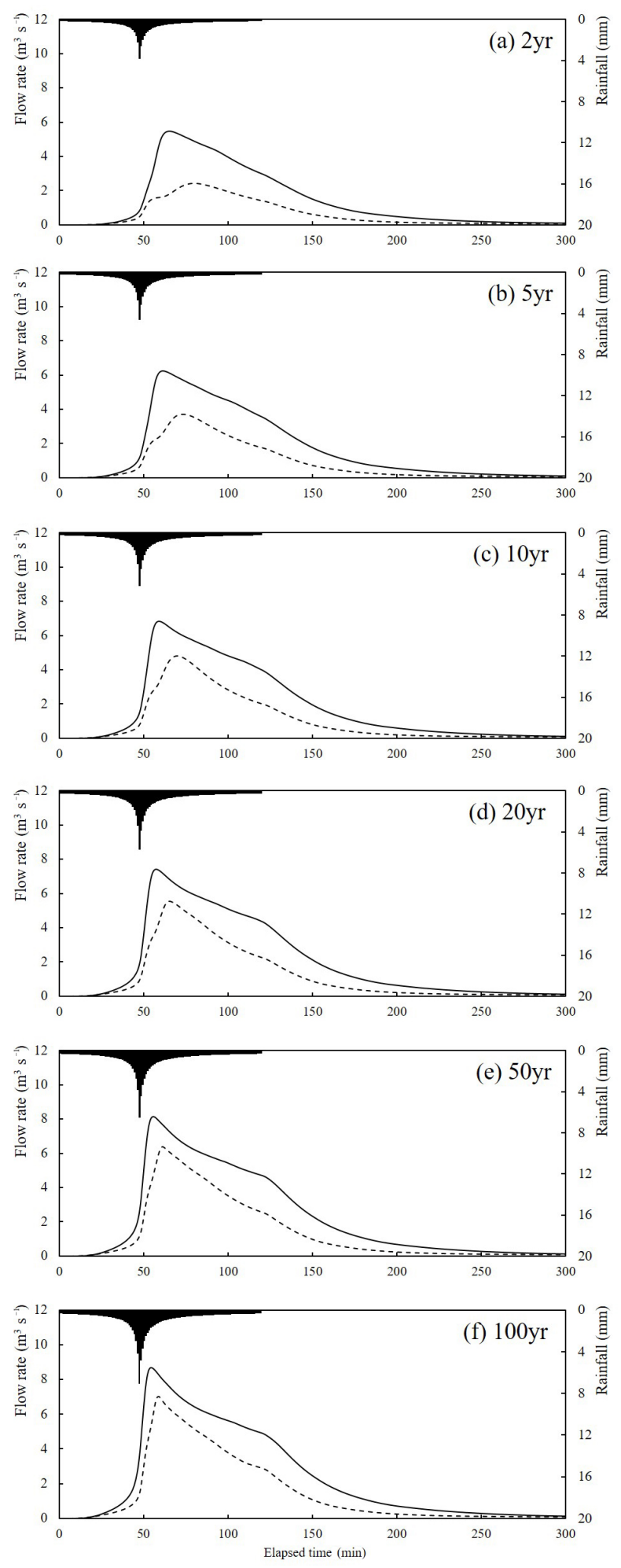

Figure 4. Runoff hydrographs for YN under baseline (solid) and SCM (dotted) scenarios for 6 modeled rainfall events (black-shaded curve). 
were $28.1-72.1,19.0-69.2$, and $33.9-56.0 \%$, respectively, under six rainfall events with return periods ranging from 2 to 100 years, and the mean reduction rates of the average flow, peak flow, and total flood volume are 44.2, 37.4, and $42 \%$ for the six rainfall return periods, there are significant differences in flow process between the BL and SCM scenarios.

For all events, the peak flow is reduced under the SCM scenario, though this effect is most pronounced at lower rainfall intensities, indicating that SCM implementation relieves the runoff concentration of storm water and reduces the flood load of YN's urban drainage system.

\subsection{Detailed hydrologic performance}

We next considered the inundation risk value for each manhole in YN (Fig. 5) for each rainfall period in both scenarios. As the risk value increased, the inundation risk of the manholes also increased, allowing the evaluation of relative risk. Inundation risk factors for each specific manhole are shown in Fig. 5. As the rainfall return period increases, inundation risk rises under both the BL and SCM scenarios, though the SCM implementation clearly reduces this risk dramatically even under intense rainfall events.

Manholes N7, N14, N17, N20, and N21 consistently show the highest inundation risk because of poor drainage systems upstream. According to on-site investigations, N7 was connected to a large, mostly impervious area, and the others were located downstream of a community area with low gradients in downstream pipes. In addition, these five manholes are at the junctions of three drainage pipes that receive water from more than $30 \%$ of the catchment area. Thus these manholes have higher risks under the BL scenario and SCM implementation is effective at reducing inundation under heavy rains with a return period smaller than 10 years. For rainfall return periods above 10 years, the SCMs still show distinct reduction effects, but the total storm water cannot be completely handled by these installations, leading to flows exceeding the capacity of YN's urban drainage system. Because that the infiltration capacity of green infrastructure would diminish under continuous rainfall, then there should be enough green infrastructures in order to completely eliminate inundation in the drainage system. Therefore, when there is not enough space to implement green infrastructures, some gray infrastructures such as underground reservoirs and deep tunnels should be implemented in conjunction with green infrastructures.

The inundation risks of the drainage system were significantly reduced after SCMs implementation, the risk values falling below 0.2 when the rainfall return period was less than 10 years. The inundation risk increases with the increasing rainfall return periods, but increasing speed are different to each other between BL and SCM scenarios. Under the BL scenario, the inundation risk of the urban drainage system shows a continuous and sharply increase with the increasing rainfall return periods, and under SCM scenario, the inunda-
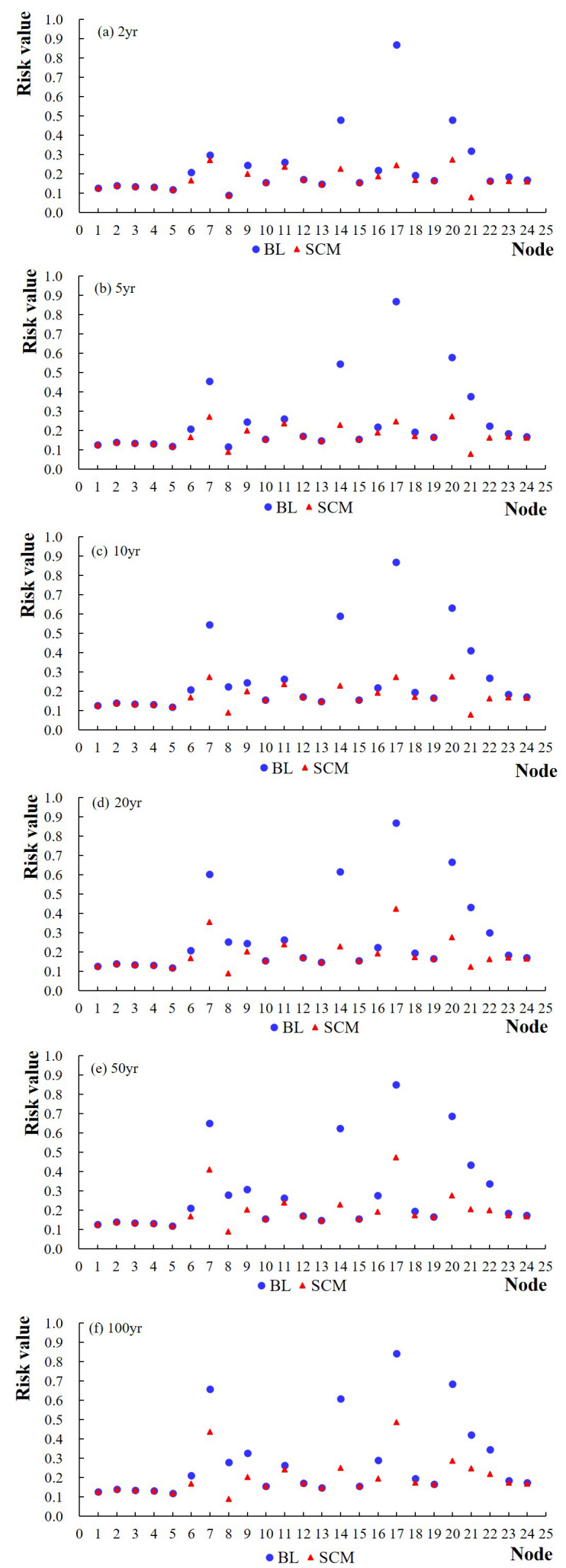

Figure 5. Risk values for each manhole in YN under BL and SCM scenarios with different rainfall return periods. 
tion risk shows no increase when the rainfall return period is lower than 5, and a slow and continuous increase when the rainfall return period is higher than 10 . The different increasing characteristics of the inundation risk for BL and SCM scenarios indicates that, the SCMs implementing acquires better effects under relatively light rains, and with increasing of the rainfall intensity, the mitigation effects of urban flood and inundation of urban drainage systems decrease gradually, which is a proof that the SCMs implementing enhances the resilience of urban drainage systems of YN to extreme rainfalls.

\section{Conclusions}

1. SCMs have significant impacts on three hydrologic performance indices related to inundation risk. The highest reduction rates of the average flow, peak flow, and total flooded volume were $72.1,69.2$, and $56.0 \%$, respectively, and the reduction rates for these decreased with increasing rainfall return period. In addition, the SCMs caused a hydrograph delay of the outfall flow from the urban drainage system; the lag time also decreased with increasing rainfall return period.

2. SCMs implementation showed an effective reduction of inundation risk in the urban drainage system. A comparison of risk values for each manhole between the BL and SCM scenarios showed that the number of inundation-affected manholes diminished from 7 to 0 under a 5 years return period rainfall, with the risk values for all manholes falling below 0.2 when the rainfall return period was below 10 years. At rainfall return periods higher than 10 years, the risk values for all manholes still fell to below 0.5 .

3. The inundation risk increases with increasing rainfall return period, but shows different characteristics between the BL and SCM scenarios. Under the former, the inundation risk shows a continuous increase with increasing rainfall return period, but under the latter, the inundation risk shows no increase when the rainfall return period is below 5 years, with a slow and continuous increase beyond that.

It could be concluded that the proper design and implementation of SCMs settings could reduce inundation risks in urban drainage systems and achieve the sustainability objectives of storm water management at a community scale. These conclusions can guide planners and decision-makers in future considerations related to inundation risk management in community-scale urban drainage systems.

Data availability. The data are not publicly accessible.
Competing interests. The authors declare that they have no conflict of interest.

Special issue statement. This article is part of the special issue "Innovative water resources management - understanding and balancing interactions between humankind and nature". It is a result of the 8th International Water Resources Management Conference of ICWRS, Beijing, China, 13-15 June 2018.

Acknowledgements. The authors would like to extend their thanks to the Chinese National Natural Science Foundation (No. 51522907 \& 51739011), and the National Key Research and Development Program of China (2016YFC0401401). This work was supported by the Research Fund of the State Key Laboratory of Simulation and Regulation of Water Cycle in River Basin, China Institute of Water Resources and Hydropower Research (grant number 2017ZY02).

Edited by: Wenchao Sun

Reviewed by: two anonymous referees

\section{References}

Chui, T. F. M., Liu, X., and Zhan, W.: Assessing costeffectiveness of specific LID practice designs in response to large storm events, J. Hydrol., 533, 353-364, https://doi.org/10.1016/j.jhydrol.2015.12.011, 2016.

Dash, A. K., Bhattcharjee, R. M., and Paul, P. S.: Lessons Learnt from Indian Inundation Disasters: An Analysis of Case Studies, Int. J. Disaster Risk Red., 20, 93-102, https://doi.org/10.1016/j.ijdrr.2016.10.013, 2016.

Hu, M., Sayama, T., Zhang, X., Tanaka, K. K., Takara, H., and Yang, H.: Evaluation of low impact development approach for mitigating flood inundation at a watershed scale in China, J. Environ. Manag., 193, 430-438, https://doi.org/10.1016/j.jenvman.2017.02.020, 2017.

Islam, M. S., Swapan, M. S. H., and Haque, S. M.: Disaster risk index: How far should it take account of local attributes?, Int. J. Disaster Risk Red., 3, 76-87, https://doi.org/10.1016/j.ijdrr.2012.10.001, 2013.

Jacobson, C. R.: Identification and quantification of the hydrological impacts of imperviousness in urban catchments: a review, J. Environ. Manag., 92, 1438-1448, https://doi.org/10.1016/j.jenvman.2011.01.018, 2011.

Jenifer, M. A. and Jha, M. K.: Comparison of Analytic Hierarchy Process, Catastrophe and Entropy techniques for evaluating groundwater prospect of hard-rock aquifer systems, J. Hydrol., 54, 605-624, https://doi.org/10.1016/j.jhydrol.2017.03.023, 2017.

Jiao, S., Zhang, X., and Xu, Y.: A review of Chinese land suitability assessment from the rainfall-waterlogging perspective: Evidence from the Su Yu Yuan area, J. Clean. Prod., 144, 100-106, https://doi.org/10.1016/j.jclepro.2016.12.162, 2017.

Kim, Y., Kim, T., Park, H., and Han, M.: Design method for determining rainwater tank retention volumes to control runoff 
from building rooftops, KSCE J. Civ. Eng., 19, 1585-1590, https://doi.org/10.1007/s12205-013-0269-1, 2015.

Liu, W., Chen, W., and Peng, C.: Assessing the effectiveness of green infrastructures on urban flooding reduction: A community scale study, Ecol. Model., 291, 6-14, https://doi.org/10.1016/j.ecolmodel.2014.07.012, 2014.

Palla, A. and Gnecco, I.: Hydrologic modeling of Low Impact Development systems at the urban catchment scale, J. Hydrol., 528, 361-368, https://doi.org/10.1016/j.jhydrol.2015.06.050, 2015.

Pochwa, K., Słys, D., and Kordana, S.: The temporal variability of a rainfall synthetic hyetograph for the dimensioning of stormwater retention tanks in small urban catchments, J. Hydrol., 549, 501511, https://doi.org/10.1016/j.jhydrol.2017.04.026, 2017.

Pyke, C., Warren, M. P., Johnson, T., LaGro Jr., J., Scharfenburg, J., Groth, P., Freed, R., Schroeer, W., and Main, E.: Assessment of low impact development for managing stormwater with changing precipitation due to climate change, Landsc. Urban Plan., 103, 166-173, https://doi.org/10.1016/j.landurbplan.2011.07.006, 2011.
Todeschini, S., Papiri, S., and Ciaponi, C.: Performance of storm water detention tanks for urban drainage systems in northern Italy, J. Environ. Manag., 101, 33-45, https://doi.org/10.1016/j.jenvman.2012.02.003, 2012.

Wang, L.: The Research on Urban Drainage Network Inundation Evaluation and Control Based on Modeling Technology, Beijing University of Technology, Beijing, 2010.

Zhao, G., Shi, R., Pang, B., Xu, Z., Du, L., and Chang, X.: Impact of rapid urbanization on rainfall-runoff processes in urban catchment: Case study for Liangshui River basin, J. Hydroelectr. Eng., 35, 55-64, 2016 (in Chinese).

Zhu, Z., Chen, Z., Chen, X., and He, P.: Approach for evaluating inundation risks in urban drainage systems, Sci. Total Environ., 553, https://doi.org/10.1016/j.scitotenv.2016.02.025, 2016. 